LA-UR- $-87-3036$

DE88 000531

TITLE

THE LOS ALAMOS PHOTOINJECTOR PROGRAM

AUthon(S) R. L. Sheffield, E. R. Gray, and J. S. Fraser

Submitied to Ninth International FEL Conference, Williamsbure. Virginio

September $14-18,1987$

\title{
DIST 'I.AIMEK
}

\begin{abstract}
Ihis epert wiss prepured as an ilccount of work sponsored by un ugency of the I Imted Stutes (iwvernment. Neither the U/nited Stales (iuvernment nor any agency thereof. nor any of their

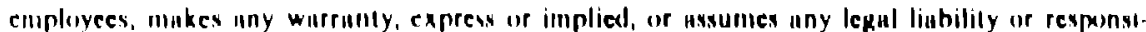
bility for the accuriscy, compleceness, or usefulness of any informulion, "pporatus, proxluci, of prexess disclosed, or represents that its use would not infringe privutely owned rights Reterence herein in any specilir: commerciul proxluct. process, or service hy trude nume, trudemurk. minuficturer, or otherwise deses not necessarily cunstilute or imply its endoraement, recom.

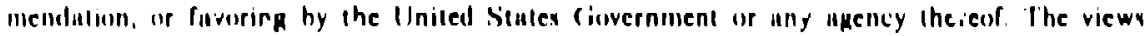

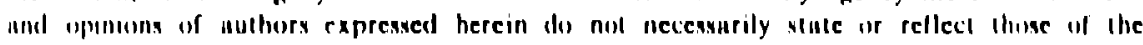
Iluled siatex Government or any unency thereof
\end{abstract}




\title{
THE LOS ALAMOS PHOTOINJECTOR PROGRAM*
}

\author{
R. L. SHEFFIELD (MS H825), E. R. GRAY, and J. S. FRASER**
}

Los Alamos National Laboratory Los A lamos, NM 87545

Free-electron lasers (FELS) require electron beams of high peak brightness. In this presentation, we describe the design of a compact high-brightness electron source for driving short-wavelength FELs. The experiment usts a laser-illuminated $\mathrm{Cs}_{3} \mathrm{Sb}$ photoemitter located in the first of cavity of an injector linac. The photocathode source and associated hardware are described. The doubled YAG laser $(532 \mathrm{~nm})$, which is used to drive the photocathode, produces 75 -ps micropulses at $108-\mathrm{MHz}$ repetition rate and peak powers of approximately $300 \mathrm{~kW}$. Diagnostics include a pepper-pot emittance analyzer, a magnetic spectrometer, and a 4-ps resolution streak camera. Present experiments give the following results: micropulse current amplitudes of $100 \mathrm{~mA}$ to $400 \mathrm{~A}$, beam emittances ranging from $10 \mathrm{n} \cdot \mathrm{mn} \cdot \mathrm{mrad}$ to $40 \mathrm{n} \cdot \mathrm{mm} \cdot \mathrm{mrad}$, an energy spread of $\pm 3 \%$, and peak current densities of $600 \mathrm{~A} / \mathrm{cm}^{2}$.

The experiment's design has now been changed to include a separately phased If cavity immediati' following the first cavity. This modification enables us to study the effects of phasing with the possibility of improving the injector performance. Also, this change will improve the vacuum conditions in the photoelectron source with a consequent improvement in lifetime performance. A brief discussion on the possible applications of this very bright and compact eisctron source is presented.

\footnotetext{
Work performed under the auspices of the U.S. Dept. of Energy and supported by the U.S. Army Strategic Defense Command.

*P. O. Box 1341. Ganges, British Columbia, VOS 1 EO, Canada
} 


\section{Introduction}

An FEL oscillator, driven by an rf linac, requires a train of low-emittance, high-current electron bunches delivered to an undulator. A conventional electron source consists of a dc electron gun, subharmonic bunchers to increase the peak current. and matching optics to conserve the beam brightness after introduction in to the accelerator. The decrease in beam quality is not acceptable for advanced high-power and/or short-wavelength FELs. A new type of accelerator electron source has been demonstrated that uses a laser-illuminated photoemitter. The approach eliminates a conventional buncher system and thereby avoids the usual large loss in brightness that occurs in bunchers.

In 1985, the achievement of high-peak currents from a $\mathrm{Cs}_{3} \mathrm{Sb}$ photocathode was reported [1]. More recently, it has been shown that the laser-driven photoca thode produces an intrinsically bright beam [2]. It remaius to te demonstrated that short bunches can be accelerated to relativistic energies without loss of brightness. With suitably short lasar pulses incivent on a photo:athode that has a high quantum efficiency, it would appear to be a straightfor ward matter to create a high-brightness, optically chopped beam, accelerate it in several of cavities, and then deliver it to the main rf linac.

A laser-illuminated photocathode can readily produce the electron bunch train that is required by rf linac-driven FEL oscillators. The emitta:uce-gro'Nth problem associated with high space-charge density in short bun thes can be alleviated by choosing an injector design that retains the requisite high-average current but accelerates, initially, a relatively long bunch. The longer bunch is best accelerated in a lower frequency linnc operated at a subharmonic of the main linac frequency. After acceleration to several nillion electron volts, a magnetic phase compressor shortens the bunch. 
A laser-illuminated photocathode can be used in a de-gun configuration in much the same way that it is employed in the laser-klystron [3] or lasertron [4]. In an $f$ cavity, on the other hand, a more rapid acceleration rate can be achieved than in a dc gun. The rf gun forms the heart of an experimental program [5] at the Los Alamos National Laboratory to develop an intrinsically bright electron source for linacs. A similar program based on a dc gun is under way at Stanford University [6].

\section{Electron·Source Brightness}

The normalized peak brightness is defined as

$B_{n}=V\left(\varepsilon_{x} \varepsilon_{y}\right) \quad\left[\right.$ units: $\left.A /\left(\mathbf{m}^{2} \cdot \operatorname{rad}^{2}\right)\right]$,

where $I$ is the peak current and $\varepsilon_{x}$ and $\varepsilon_{y}$ are the normalized transverse emittances of the beam [7]. In accelerator discussions, it is constructive to use the rms emittance formulation, defined as

$E_{x}=4 \pi\left[\left\langle x^{2}\right\rangle\left\langle x^{12}\right\rangle-\left\langle x x^{\prime}\right\rangle^{2}\right]^{1 / 2}$,

where $x$ and $x^{\prime}$ are the particle's transverse coordinate and angle of divergence from the optic axis, respectively, and $<>$ means an average over the electron distribution. In this formulation, the rms emittance is equal to the total phasespace area for a Kapchinskii-Vladimirskii distribution [8]. The normalized emittance is then 
$\varepsilon_{n}=\gamma \beta c$

where for an azimuthally symmetric beam $\varepsilon=\varepsilon_{x}=\varepsilon_{y}$.

The lower limit of the beam's normalized emittance from a thermionic electron source is governed by the cmitter size and by the transverse component of the thermal motion of the electrons. The thermal limit of the normalized rms emittance of a beam from a thermionic emitter of radius $r_{c}$ at a uniform absolute temperature $\mathrm{T}$ is [9]

$\varepsilon_{n}=2 \pi r_{c}\left[k T / m_{0} c^{2}\right]^{1 / 2} \quad$ (units: $\left.m \cdot r a d\right)$

because $\left\langle\mathrm{xx}^{\prime}\right\rangle=0$ at the cathode. For a typica! thermionic emitter at $1160 \mathrm{~K}$, the average transverse energy of emitted electrons is $0.1 \mathrm{eV}$. For a uniform current density $\mathrm{J}$, the total current is $I=\pi r_{\mathrm{e}}{ }^{2} \mathrm{~J}$ and the lower limit on the rms emittance is

$\varepsilon_{n}=5.0 \times 10^{-6} \mathrm{n}(\mathrm{V} /)^{1 / 2} \quad$ with $\mathrm{J}$ in $\mathrm{A} / \mathrm{cm}^{2}$.

The corresponding normalized paak brightness is limited to

$B_{n}=I / \varepsilon_{n}^{2}=4.1 \times 10^{\circ} \mathrm{J}$

The current density from 9 dispenser cathode is typically not more than $10 \mathrm{~A} / \mathrm{cm}^{2}$; therefore, for an emitting area of $1 \mathrm{~cm}^{2}$, the ratio $\mathrm{V} / \mathrm{J}$ is of the order unity. Semiconductor phntoemitters, on the other hand, are capable of delivering 5 over $500 \mathrm{~A} / \mathrm{cm}^{2}$, and their effective temperature ${ }^{2}$ is low enough to 
produce beams an crder of magnitude brighter than those from thermionic cathodes.

\section{The Los Alamos Photoinjector Program}

The Los Alamos program is based on an rf cavity with a photoca thode electron source. The initial rf gun experiments were carried out at a irequency of $1300 \mathrm{MHz}$ because a powerful klystron was available. A schematic diagram of the single cavity Los Alamos injector experiment is shown in fig. 1.

\subsection{Photocathode Design}

In recent, years, photocathodes for polarized electron sources have been made from wafers of GaAs $[10,11]$. Current densities as high as $180 \mathrm{~A} / \mathrm{cm}^{2}$ have been reported [11]. Photoemitters of $\mathrm{Cs}_{3} \mathrm{Sb}$ are less demanding of system cleanliness [12] than are those of $\mathrm{GaAs}$. An additional advanctage of a positive electron affinity semiconductor like $\mathrm{Cs}_{3} \mathrm{Sb}$ lies in the rapid emission of the photoelestrons [12]. By contrast, the intrinsic emission-time uncertainty of $G_{2} A s$ has been measured in the range from 8 to $71 \mathrm{ps}$ for active layers between $50 \mathrm{~nm}$ and $2 \mu \mathrm{m}$ in thickness [13].

$\mathrm{A} \mathrm{Cs}_{3} \mathrm{Sb}$ photocathode was chosen for its ease of preparation within the vacuum environment of the linac and for its relative toierance of vacuum conditions in the injector linac [12]. A photoinject.r. 1; rac must bu bakeable in its entirety to about $200^{\circ} \mathrm{C}$ and be capable of maintaining a pressure below $10^{-9} \mathrm{tnrr}$, preferably $10^{-10}$ torr. If a $\mathrm{Cs}_{3} \mathrm{Sb}$ photocathode is damaged in use, the damage cain be erased by heating to $400^{\circ} \mathrm{C}$, then a new one prepared in situ. 
The spectral response [14] of $\mathrm{Cs}_{3} \mathrm{Sb}$ extends from a quantum energy of $1.8 \mathrm{eV}(\mathrm{A}=690 \mathrm{~nm})$ to energias greater than $3.8 \mathrm{eV}(\mathrm{A}<320 \mathrm{~nm})$. Therefore, $\mathrm{a}$ $\mathrm{Cs}_{3} \mathrm{Sb}$ photocathode can be used with a Nd:YAG laser with frequency doubled $(A$ $=532 \mathrm{~nm})$ or tripled $(\mathrm{A}=355 \mathrm{~nm})$. A Nd:YAG laser can readily be mode locked to deliver trains of 70 -ps pulses at a microscopic repetition rate in a range from 50 to $120 \mathrm{MHz}$.

\subsection{RF Gun Design}

The thermal energy of the electrons as they leave the surface of the photoemitter is low. However, the transient forces to which an intense bunch is subjected as it emerges into strong acceleratiag field are large and are comparable to the space-charge force.

Jones and Peter [15] have shown the importance of nonlinear forces in detailed simulation calculations of the transport of very short electron bunches in dc and if fields. Emittance growth is minimized if at least two conditions are met: (1) the current density in the bunch is uniform and therefore the space-charge force is linear in the radial direction and (2) the cavity field (in the absence of space charge) is radially linear. The latter condition is satisfied if the cavity wall shape is given by

$$
\rho^{2}=2\left((\Psi-\zeta)(1-2 \mu)+\zeta^{3} / 3-\mu \zeta^{2} \mid /(\zeta-\mu) .\right.
$$

where $\rho=r / z_{0}, \zeta=z / z_{0} \Psi=-\phi / E_{0} z_{0}$, and $\phi$ is the electric potential; $E_{O}$ is the (axial) electric fieid at the origin $(r=0, z=0)$. The radial electric field is given by $E_{\rho}=\rho(\zeta-\mu)$. The position at which t'se axial electric field vanishes for $r=$ 
0 is denoted by $z_{0}$, and $\mu$ is an arbitrary focusing parameter. For $0<\mu<0.5$, the radial electric field exerts a focusing force in the region $0<z<\mu z_{O}$.

In a bunch of finite length, the electrons in the leading- and trailing-edge regions are acted upon by the large, nonlinear, transient longitudinal forces arising from the large rate of change in the total current. These forces lead to emittance growth that is reduced by using long pulses in which the hot end regions form a smaller fraction of the whole. The cavity walls near the bearr axis are shaped according to the above equation for $p^{2}$. The focusing parameter $\mu$ was chosen to be 0.15 , a value that gives minimum emittance growth [16], and the scaling parameter $z_{0}=4.0 \mathrm{~cm}$ was used. The outer part of the rf gun cavity was shaped to maximize the cavity quality factor $Q$. Fig. 2 shows the ri gun cavity designed for an operating frequency of $1300 \mathrm{MHz}$. Plots of the radial electric fiel $]$ for different $Z$ values obtained from the code SUPERFISH for a zonventional high $Q$ cavity and linear field cavity are shown in figs. 3 and 4 , respectively. The specially designed cavity is much more linear than the corresponding fields in a more conventional of cavity optimized for high shunt impedance.

\subsection{Single-Cavity Experimental Results}

Initial observation of the accelerated electron beam from the rf gun was obtained with the wall-current monitor shown in Fig. 1. With a fast oscilloscope, the largest pulse trains repeatedly observed had peak amplitudes of $4.4 \mathrm{~V}$ with $40 \mathrm{~dB}$ of attenuation in place. The measured bunch charge, obtained from the integrated pulse profiles, wr s $27 \mathrm{nC}$, giving an average current in the pulse train of 2.9 A. Assuming that the temporal profile was Gaussian (see below), the peak current was $390 \mathrm{~A}$. The probable error in these measurements is $\pm 20 \%$. 
The minimum laser pulse width observed was $53 \pm 1$ ps FV/HM; on the same streak-camera sweep, the electron bunch widths were the same to within the experimental error when allowance was made for the observed 6\% energy spread. We conclude, therefore, that for the present experimental conditions, the pulse broadening introduced by the $\mathrm{Cs}_{3} \mathrm{Sb}$ photoemission is less than $2 \mathrm{ps}$.

The emittance of space-charge-dominated beams was measured with peak currents ranging from 100 to $150 \mathrm{~A}$. Three measurement sets were made under various combinations of peak current and focusing strength in the first solenoid (table 1). The normalized emittance for $130 \mathrm{~A}$ peak was $20 \pi \cdot \mathrm{mm} \cdot \mathrm{mrad}$. The corresponding normalized peak brightness was $-4 \times 10^{10} \mathrm{~A}^{\prime}\left(\mathrm{m}^{2} \cdot \mathrm{rad}\right)$, and the average macropulse current was $-1.0 \mathrm{~A}$. The estimated probable error on all these measurements is $\pm 20 \%$. No corrections have been made for space-charge effects. The beam energy measured on the double-focusing spectrometer agreed within $10 \%$ of the predicted value, $1.1 \mathrm{MeV}$. The measured energy spread was $\pm 3 \%$.

\section{Two-Cavity Experiment}

The second phase of this experimental program is to improve the vacuum conditions in the injector photocathode region and to study the effects of selative phasing using two of cavities on the electron beam emittance. The new experimental configuration is shown in fig. 5 . A new vacuum photocathode preparation unit and direct vacuum pumping on the of cavities have been added. Also a second rf cavity, designed with linear radial electric fields, inmediately follows the first cavity. 


\section{Conclusions}

The photoinjector experiment demonstrated the predicted performance in yield and temporal response and exceeded expectitions in current density and brightness. The temporal profile measurements prove that the emission time uncertainty is less than $10 \mathrm{ps}$. The two-cavity experiment has been assembled and is now being tested.

\section{Acknowledgments}

The authors are grateful to Jerry Watson, for continued support and encouragement. The duthors are indebted to Scott Apgar, Jake Chavaz, Renee Feldman, Paul Giles, Bob Hoeberlin', Ted Gibson, Don Green wood, Valerie Loebs, Paul Martinez, Richard Martinez, Dinh Nouyen, Noel Okay, Louis Rivera, Jake Salazar, Boyd Sherwood, Robert Springer, Robert Stockley, Floyd Sigler, Scott Volz, and Reine Musset for assistance in the design, construction, and operation of the experiment. 
References

[1] C. H. Lee, P. E. Oettinger, E. R. Pugh, R. Klinkowstein, J. H. Jacob, J. S. Fraser, and R. L. Sheffield, "Electron Emission of Over $200 \mathrm{~A} / \mathrm{cm}^{2}$ from a Pulsed-Laser Irradiated Photocathode," IEEE Trans. Nucl. Sci. 32 (5), 3045 (1985).

[2] P. Oettinger, I. Bursuc, R. Shefer, and E. Pugh, "Brightness of an Intense Electron Beam Generated by a Pulse-Laser Irradiated Photocathode," Proc. 1987 Particle Accelerator Conf., Washington, D.C., March 16-19, 1987 , to be published.

[3] G. A. Loew, "The SLAC Linear Collider and a Few Ideas on Future Linear Colliders," Proc. 1984 Linac Conf., Gesellschaft für Schwerionenforschung, Darmstadt report GSI-84-11, 282 (September 1984).

[4] M. Yoshioka, M. Mutuo, Y. Fukushima, T. Kamei, H. Matsumoto, H. Mizuno, S. Noguchi, J. Sato, T. Shilara, T. Shintake, K. Takata, H. Kuroda, N. Nakano, H. Nishimura, F. Soda, M. Miyao, Y. Kato, T. Kanabe, and S. Takeda, "Lasertron: Laser Triggered RF-Source for Linacs in TeV Region, "Proc. 1984 Linac Conf., Gesellschaft für Sch werionenforschung, Darmstadt report GSI-84-11, 469 (September 1984).

[5] J. S. Fraser, R. L. Sheffield, E. R. Gray, P. M. Giles, R. W. Springe: , and V. A. Loebs, "Photocathodes in Accelerator Applications," Proc. 1987 Particle Accelerator Conf., Washington, D.C., March 16-19, 1987, to be published.

[6] T. I. Smith, "Intense Low Emittance Linac Beams for Free Electron Lasers," 1986 Linear Conf. Proc., Stanford Linear Accelerator Center report, SLAC-303, 421 (1986). 
[7] C. LeJeune and J. Aubert, "Emittance and Brightness: Definitions and Measurements," Applied Charge Particle Optics, A. Septier, ed., Advances in Electronics and Electron Physics, Supp. 13A, 159 (1980).

[8] P. Lapostolle, "Possibie Emittance Increase Through Filamentation Due to Space Charge In Continuous Beams," IEEE Trans. Nucl. Sci. 18 (3), 1101 (1971).

[9] J. D. Lawson. The Physics of Charged Particle Beams, (Oxford University Press, 1977), p. 199.

[10] D. T. Pierce, R.J. Ceiouta, G.C. Wang, W. N. Unertl, A. Galens, C. E. Kuyatt, and S. R. Mielczarek, "GaAs Spin Polarized Electron Source," Rev. Sci. Instrum. 51, 473 (1980).

[11] C. K. Sinclair and R. H. Miller, "A High Current, Short Pulse, RF Synchronized Electron Source for the Stanfe rd Linear Collider," IEEE Trans. Nucl. Sci. 28 (3), 2649 (1981).

[12] C. H. Lee, P. E. Oettinger, A. Sliski, and M. Fishbein, "Practical Laser Activated Photo-emissive Electron Source," Rev. Sci. Tnstrum. 56, (4) 560 (1985).

[13] C. C. Phillips, A. E. Hughes, and W. Sibbett, Photochron Streak Camera with GaAs Photo-Caihode," in Ultrafast Phenomena IV, D. H. Auston and K.W.B. Eisenthal, :ds., (Springer-Verlag, Berlin, 1984) p. 420.

[14] W. E. Spicer, "Photoemissive, Photoconductive, and Optical Absorption Studies of Alkali-Antimonide Compounds," Phys. Rev. 112, 114 (1958).

[15] M. E. Jones and W. K. Peter, "Theory and Simulation of High-Brightness Electron Beam Production From Laser-Irradiated Photocathodes in the Presence of DC and RF Electric Fields," Proc 5th Int. Conf. on High-Power Ya-ticle Beams, Kobe, Japan, 1986, to be published. 
[16] M. E. Jones and W. K. Peter, "Particle-in-Cell Simulations of the Lasertron," IEEE Trans. Nucl. Sci. 32 (5), 1794 (1985).

\section{Figure Captions}

Fig. 1. Plan view of the photoinjector experiment.

Fig. 2. Profile of the lizear-field of gun cavity. The innor walls $\_$the cavity (radius $<2 \mathrm{~cm}$ ) are given by eq. (1) with $\psi=0$ or 0.8 , shown by dashed lines at large radii. The bore radius is $1.7 \mathrm{~cm}$.

Fig. 3. The radial electric fields near the axis of a conventional rf accelerator cavity optimized for high srunt impedance (within the cross-hatched area of the inser.

Fig. 4. The radial fields near the axis of the of gun cavity (within the crosshatched area ir the itsert). The bore radius is $1.3 \mathrm{~cm}$.

Fig. 5. Plan view of two-cavity photoinjector experiment.

Table 1

Emittence Measurements

\begin{tabular}{|c|c|c|c|c|c|c|c|}
\hline Set & $\begin{array}{l}\text { Peak } \\
\text { Current } \\
\text { (A) }\end{array}$ & $\begin{array}{l}\text { Lens } 1 \\
\text { Current } \\
\text { (A) }\end{array}$ & $\begin{array}{c}\text { Bunch } \\
\text { Charge } \\
\text { (nC) }\end{array}$ & $\underset{(\mathrm{mm})}{X_{m}}$ & $\begin{array}{l}X^{\prime} \text { int } \\
\text { (inrad) }\end{array}$ & $\begin{array}{c}\text { Normalized } \\
\text { Emittance } \\
(\beta Y=3.0) \\
(n \cdot \mathrm{mm} \cdot \mathrm{mrad})\end{array}$ & $\begin{array}{l}\text { Normalized } \\
\text { Brightnesg } \\
\left(\mathrm{A} /\left(\mathrm{m}^{2} \cdot \mathrm{rad}^{2}\right)\right.\end{array}$ \\
\hline 1 & 100 & 235 & 8 & 3.9 & 1.7 & 20 & $.5 \times 10^{10}$ \\
\hline 2 & $15 n$ & $3 i 0$ & 12 & 7.5 & 1.4 & 32 & $1.4 \times 10^{10}$ \\
\hline 3 & 130 & 314 & 10 & 39 & 1.5 & 18 & $4 \times 101:$ \\
\hline
\end{tabular}




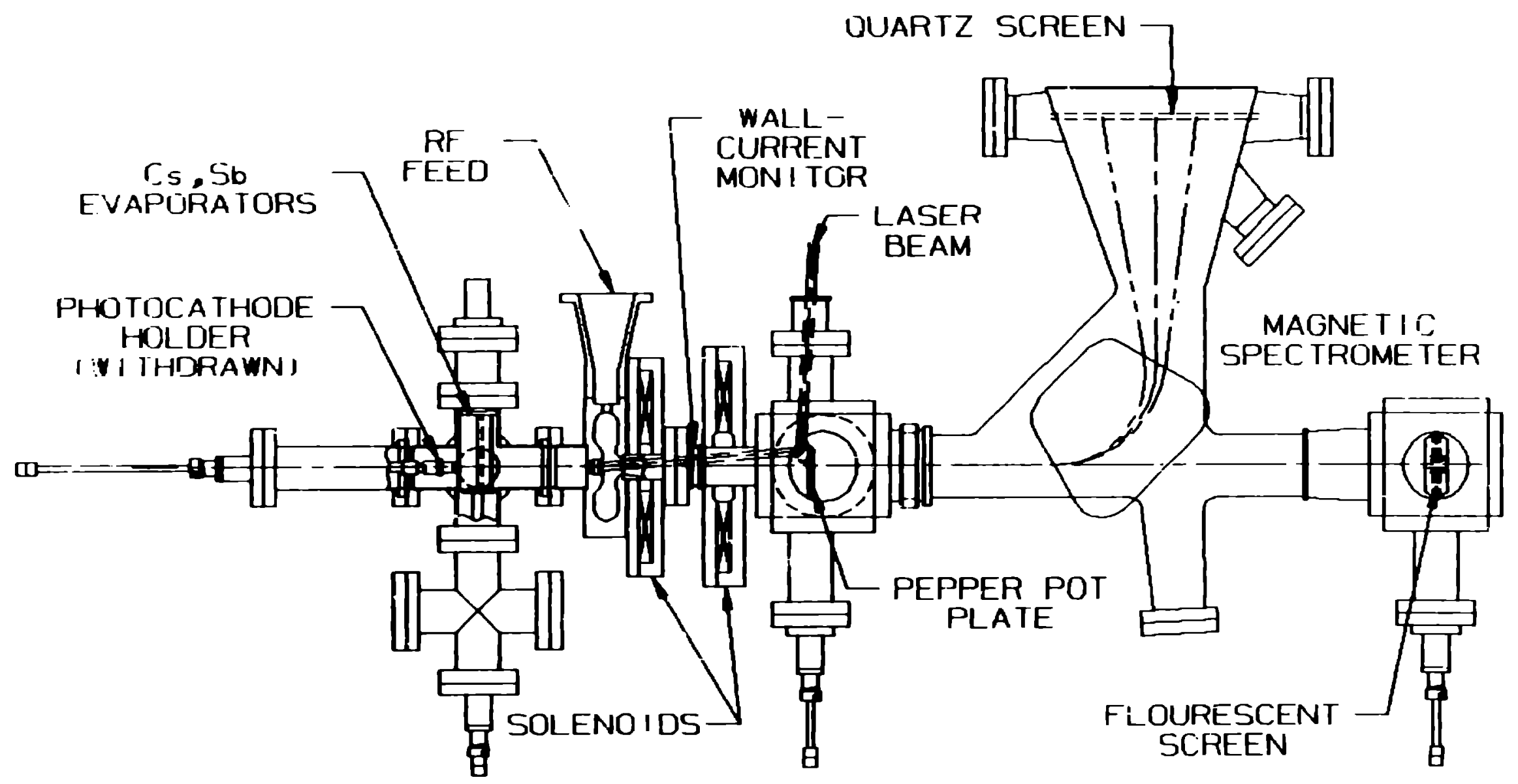


$+$

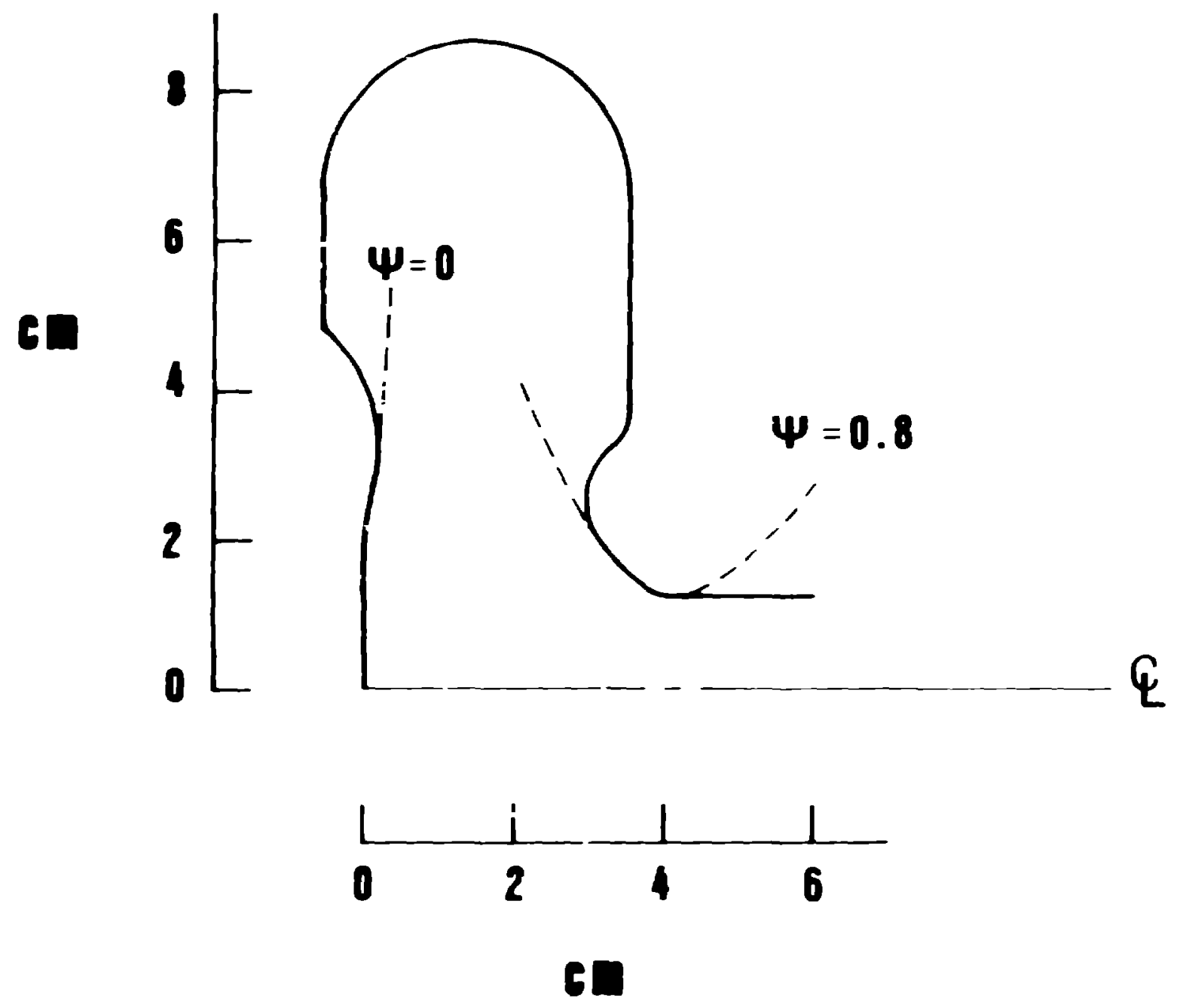

- 


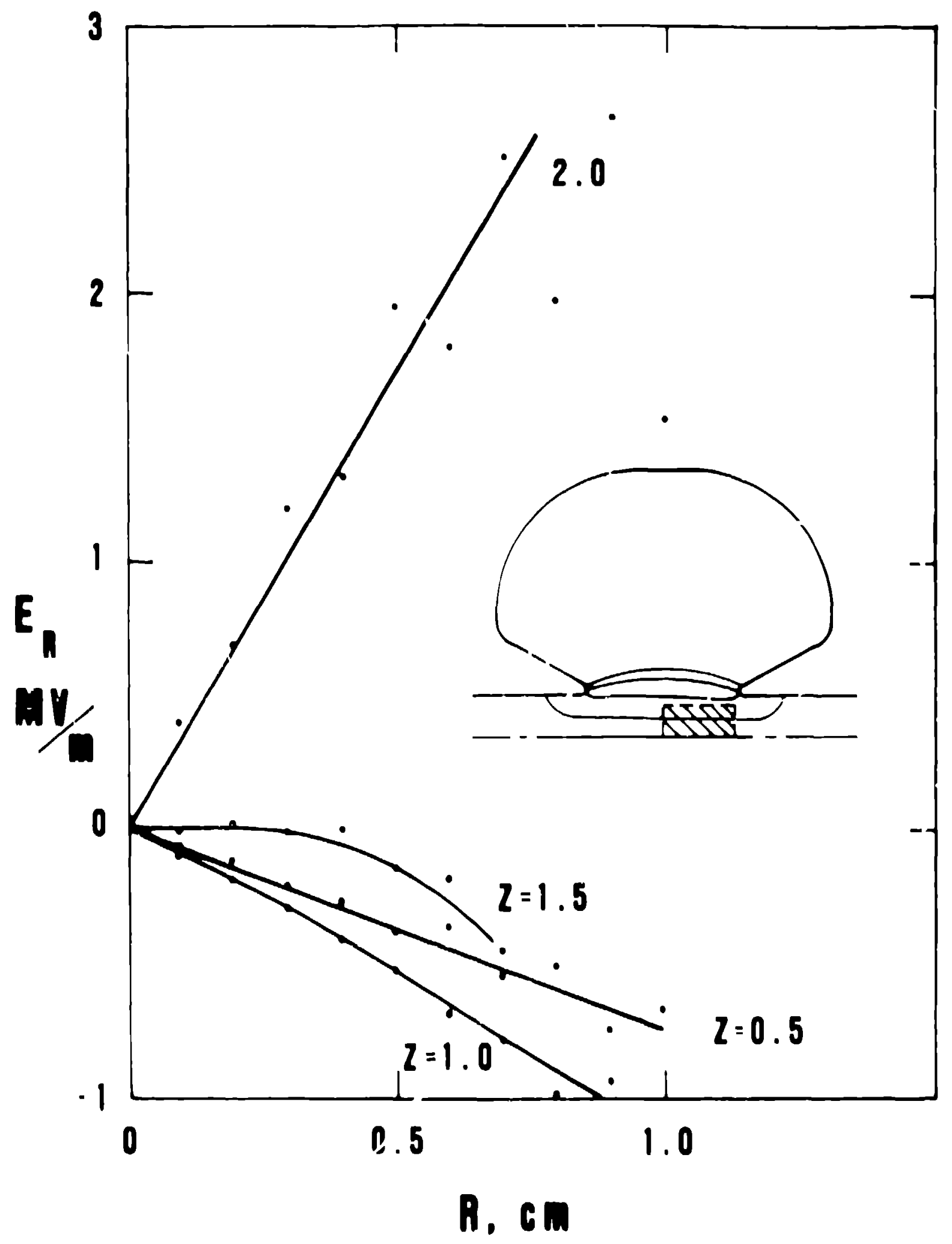




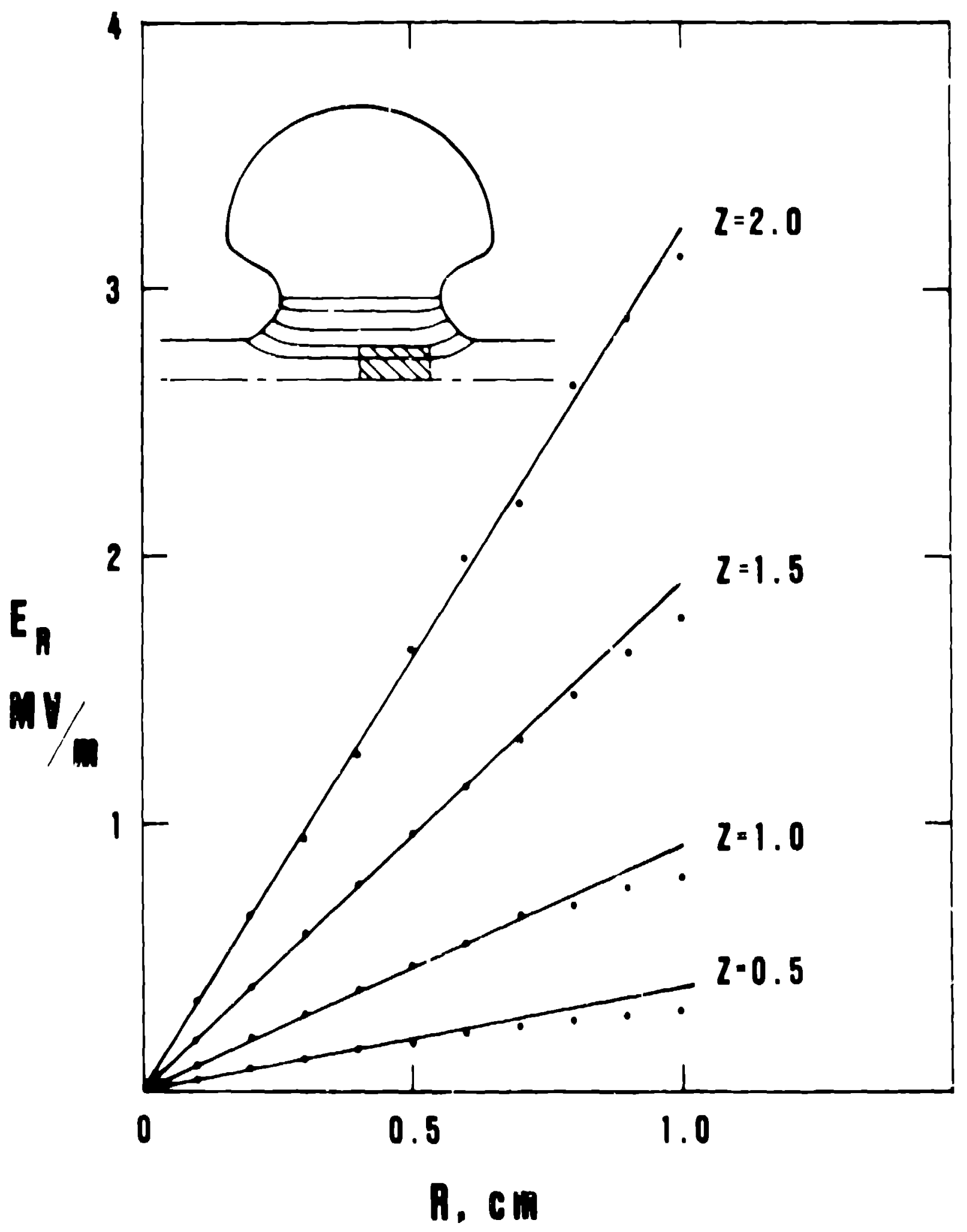

74.0100 


\section{PHOTOINJECTOR TWO CAVITY EXPERIMENT}

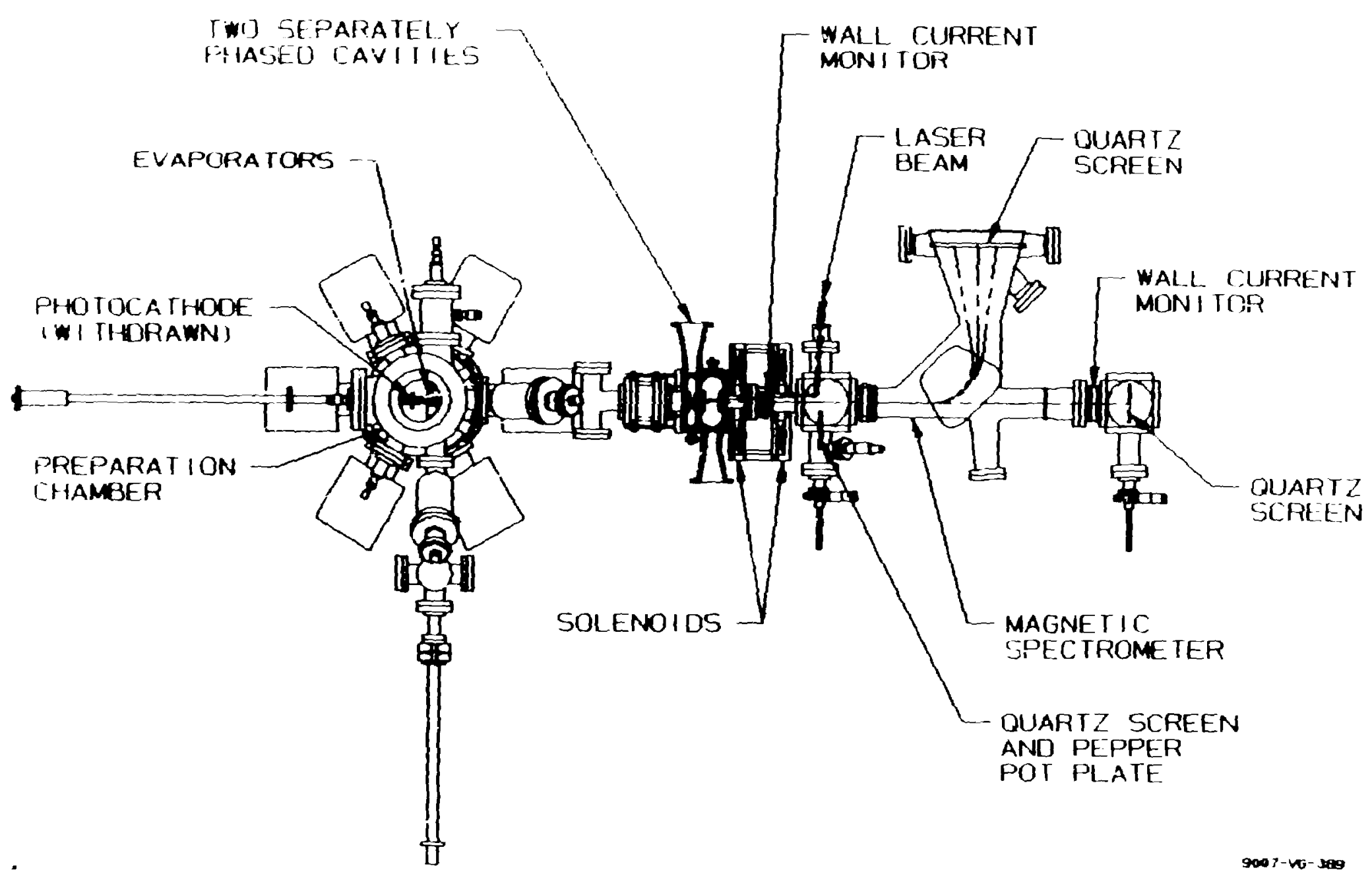

